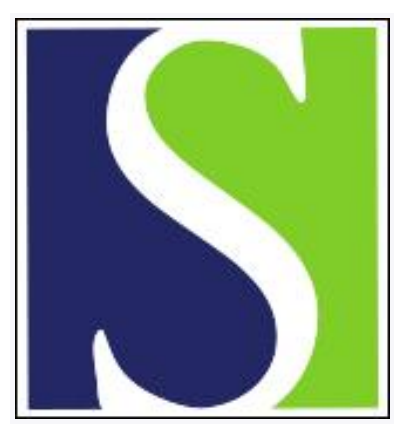

Scand J Work Environ Health 1977;3(3):122-127

https://doi.org/10.5271/sjweh.2781

Issue date: Sep 1977

Tracheobronchial deposition of inhaled particles in rabbits.

by Tomenius $L$

Key terms: aerosol; bronchus; deposition; inhaled particle; lung; particle; rabbit; tracheobronchial deposition

This article in PubMed: www.ncbi.nlm.nih.gov/pubmed/910122

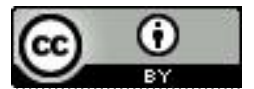




\title{
Tracheobronchial deposition of inhaled particles in rabbits
}

\author{
by LENNART TOMENIUS, M.D. ${ }^{1}$
}

\begin{abstract}
TOMENIUS, L. Tracheobronchial deposition of inhaled particles in rabbits. Scand. j. work environ. \& health 3 (1977) 122-127. Tracheobronchial deposition of inhaled particles in rabbit lung was studied after exposure to monodisperse aerosols $4-9$ $\mu \mathrm{m}$ (aerodynamic diameter). Deposition was measured in terms of the particle content in free dissected bronchial sections from formaldehyde exposed and dried lungs. The free dissected part consisted of the lower section of the trachea and the lobe bronchi with their extensions from the five lobes. Deposition in this part of the tracheobronchial tree varied according to particle size, exposure technique, and individual. The range of the individual variation was about the same $(300 \%)$ as the difference in deposition caused by changes in particle size ( 4 to $7 \mu \mathrm{m}$ ) and exposure technique (tracheal or oral tube). The individual variation could not be explained by any physiological factor, such as contraction in the respiratory tract. Rabbits treated intravenously with atropin had the same tracheobronchial deposition as a control group. On the other hand the individual variation in deposition could be explained by some anatomical factor since airway diameter and bronchial deposition showed a significant negative correlation.
\end{abstract}

Key words: aerosol, bronchus, deposition, lung, particles.

Air pollutants in particulate form represent a serious problem in the general, as well as the occupational, environment. An estimate of the health risk posed by a given inhaled particulate pollutant requires knowledge of its deposition in the lung. Information is not only needed about the total deposition, but also about deposition in the various parts of the lung. For one reason the local effects of toxic particles deposited in the trachea and the bronchi, provided as they are with glan-

1 Department of Environmental Hygiene, Karolinska Institute and the Department of Environmental Hygiene, the National Swedish Environment Protection Board, Stockholm, Sweden.

Reprint requests to: Dr. Lennart Tomenius, Department of Environmental Hygiene, National Swedish Environment Protection Board, S-104 01 Stockholm, Sweden. dular mucosa, may be completely different from the effects of the same particles deposited in the alveoli, which consist of two layers of very thin cells separated by a basal membrane.

Systemic effects may also vary with deposition. For example less soluble metal particles (e.g., lead and cadmium) deposited in the trachea and bronchi will be transported by mucociliary action to the gastrointestinal tract, where only a small fraction of the metal will be absorbed (19). If these particles are deposited in the alveoli, they are more likely to enter into the systemic circulation.

The deposition of inhaled particles in the various parts of the lung has been estimated by theoretical and experimental studies, reviews of which have been made by Hatch and Gross (6), the Task Group on Lung Dynamics (18), Stuart (16), and Mercer (12). 
The methods used to determine tracheobronchial deposition are indirect and are based on several assumptions of anatomical or physiological character. The theoretical deposition models $(1,5,9)$ are based on simplifications of the very complex anatomy of the Iung. Furthermore they only give information about deposition in "an average man," a clear disadvantage since large interindividual differences in tracheobronchial deposition, measured as 24-h lung clearance, prevail (10). Camner (2) and Lippmann et al. (11) have shown that these individual differences in lung clearance are reproducible, and therefore differences in deposition should be reproducible.

Estimations of tracheobronchial deposition based solely upon the course of lung clearance (10) can also be criticized because defective mucociliary transport cannot thereby be distinguished from low tracheobronchial deposition.

Experimental studies on lung casts (17) show that lung anatomy differences between individuals are large enough to produce local differences in the air flow and thus differences in deposition. Theoretically, deposition by impaction varies with the airway diameter.

In my study, in contrast to the earlier experimental studies that are reviewed, the estimations of deposition are based on direct observations in vivo. The deposition was measured as the particle content in free dissected bronchi from dried lungs that had been exposed to formaldehyde.

With this method it has earlier been shown that, among rabbits, the regional deposition of $7 \mu \mathrm{m}$ polystyrene particles varies largely $(20,21)$ and that these interindividual differences are reproducible (22). These findings indicate that such differences are caused mainly by biological factors and not by variations in the aerosol or in the exposure technique. It has been shown that a change in the contraction state of bronchi brings about a change in the deposition of inhaled particles (24). Whether the interindividual differences in deposition reflect differences in the state of contraction remains to be shown. The aim of this study was to clarify how the tracheobronchial deposition varies with particle size and exposure technique, with respect to individual variation, and to what extent the variation in deposition may depend on anatomical or physiological characteristics.

\section{MATERIAL AND METHODS}

'The material and methods used are described in the ensuing sections. Moredetailed information about them, as well as about possible systematical errors, has been given in earlier papers $(20,22)$.

\section{Experimental design}

The influence of variation in particle size on tracheobronchial deposition was studied in 12 rabbits exposed to a mixture of 4 and $7 \mu \mathrm{m}$ particles via a tracheal tube. The influence which variation in exposure technique might have upon deposition was studied in 12 rabbits exposed to $7 \mu \mathrm{m}$ polystyrene particles via an oral tube, after which the resulting deposition was compared with the deposition in rabbits exposed via the tracheal tube. For the evaluation of whether the individual variation is caused by a physiological factor, deposition in 13 rabbits exposed to atropin (Atropin $0.05 \% \mathrm{ACO}, 0.5 \mathrm{mg} / \mathrm{kg}$ I.V.) was compared to that in controls $(0.9 \% \mathrm{NaCl}$ solution I.V., $1 \mathrm{ml} / \mathrm{kg})$. The rabbits were exposed to $6 \mu \mathrm{m}$ teflon particles via a tracheal tube. The role which anatomical factors might play in deposition was studied when 14 rabbits were exposed to $7 \mu \mathrm{m}$ polystyrene particles via a tracheal tube and their subsequent deposition was viewed in the light of measurements of inner bronchial diameter.

\section{Test aerosols}

The test aerosols consisted of 4 and $7 \mu \mathrm{m}$ CMD (count mean diameter) polystyrene particles (density $1 \mathrm{~g} / \mathrm{cm}^{3}$ ) and $6 \mu \mathrm{m}$ CMD teflon particles (density $2 \mathrm{~g} / \mathrm{cm}^{3}$, giving an aerodynamic diameter of $8-9 \mu \mathrm{m})$. All particles were produced by spinning disc techniques $(7,14)$. The polystyrene particles were tagged with ${ }^{51} \mathrm{Cr}$ or ${ }^{46} \mathrm{Sc}(7)$. The teflon particles were tagged with ${ }^{99 \mathrm{~m}} \mathrm{Tc}(3)$. 
The particles were suspended by ultrasonic vibrations in a $0.2 \%(\mathrm{v} / \mathrm{v})$ water solution mixed with a wetting agent, trimethyl nonylether of a polyethylene glycol (Tergitol, TMM Union Carbide Chemical Co.). The particle aerosol was generated by means of spraying a maximum of 0.2 $\mathrm{ml}$ of a water suspension of particles up into a 15-1 exposure tower (7). When the rabbits were to be exposed to two aerosols simultaneously, a mixture of both was sprayed up into the exposure tower.

\section{Exposure to test aerosols}

Before the particle exposure, the rabbits were anesthetized with $30 \mathrm{mg}$ of pentobarbital (Nembutal ${ }^{\circledR}$ Abbott or Mebumal ACO) per kilogram of body weight. They were intubated with a teflon tracheal tube, the end of which was introduced $1-2 \mathrm{~cm}$ below the vocal cords.

By means of a whole-body respirator, the tidal volume was standardized to 29$32 \mathrm{ml} /$ inhalation and the breathing frequency to $20-22$ inhalations $/ \mathrm{min}$. The exposure time was $4 \mathrm{~min}$ at most.

In a few experiments rabbits were exposed through an oral tube. These experiments entailed spontaneous breathing only. The oral tube consisted of two parts: an inner curved part of plexiglass that depressed the tongue along the midline with the front end towards the dorsal side of the front teeth (length $70 \mathrm{~mm}$, diameter $8 \mathrm{~mm}$ ), and another bendable part of teflon that was connected to the exposure tower.

After exposure to the test aerosol the rabbits were sacrificed by an intravenous overdose of pentobarbital.

Immediately after death the respirator was used to ventilate the lungs for $30 \mathrm{~s}$ with saturated formaldehyde, a highly ciliostatic agent (4). The vapor was produced from heated paraformaldehyde powder.

\section{Free dissection of bronchi}

The upper part of the trachea was clamped with forceps so that the lung would not collapse; whereupon the lung was removed from the body. The lung was expanded and dried with an overpressure of $10-15 \mathrm{~cm}$ $\mathrm{H}_{2} \mathrm{O}$. All the lungs were divided into the same number of slices in a standardized way so that the same part of the tracheobronchial tree would be studied in spite of variations in size. The two lower lobes were divided into seven equally thick slices and the upper and the middle lobe into four slices each; they were cut with a razor blade from the dorsal side at a right angle to the main bronchus and its extension.

The extension of the lobe bronchus was dissected free from all slices except the one in the periphery. The bronchial branches were cut away at a short distance from the bifurcation. The lower trachea (between the carina and apex) was included in the whole lung and in the bronchial sections when the tracheobronchial deposition was determined.

Before digestion the surface was calculated from the measured length and diameter of the bronchial sections in a binocular observation microscope (BauschLomb stereozoom BVB-73) with an acular scale.

\section{Measurements of radioactively tagged particles}

The lung specimens were digested in a mixture of nitric and sulfuric acid in the proportion $3: 1$ so that a standardized geometry would be achieved for the activity measurements. These were performed in a well counter or a whole-body counter, connected to a Packard Spectrometer. The content of particles in different lung sections was determined by measurement of the activity at the photo peak for ${ }^{99 \mathrm{~m} T \mathrm{~T}}$ $(0.14 \mathrm{MeV}),{ }^{51} \mathrm{Cr}(0.32 \mathrm{MeV})$, and ${ }^{46} \mathrm{Sc}(0.89$ $\mathrm{MeV}$ ). When rabbits were exposed to a mixture of two aerosols of particles tagged with different radionuclides, the ${ }^{46} \mathrm{Sc}$ activity superimposed in the ${ }^{51} \mathrm{Cr}$ channel was taken into account.

\section{Tracheobronchial deposition}

Tracheobronchial deposition was measured in terms of particle content in the free dissected part of the tracheobronchial tree as the percentage of the particle content in the whole lung. 


\section{RESULTS}

Variation in deposition with

particle size

In the 12 rabbits exposed to a mixture of aerosols of $4 \mu \mathrm{m}\left({ }^{46} \mathrm{Sc}\right.$ tagged) and $7 \mu \mathrm{m}$ $\left({ }^{51} \mathrm{Cr}\right.$ tagged) particles, the tracheobronchial deposition of $7 \mu \mathrm{m}$ particles, on the average, was found to be greater than that of $4 \mu \mathrm{m}$ particles (mean $\pm \mathrm{SD}: 10.7 \pm 3.2$ and $2.5 \pm 1.1$, respectively).

Exposure to the mixture of 4 and $7 \mu \mathrm{m}$ polystyrene particles brought about considerable interindividual differences in deposition. The deposition of the two types of particles correlated significantly $(\mathrm{r}=$ 0.90) (fig. 1). The biological factors which must cause the differences in deposition between individuals do so in the same direction and in proportion to each other for 4 and $7 \mu \mathrm{m}$ particles.

Variation in deposition with exposure technique

The tracheobronchial deposition in the 12 rabbits exposed to $7 \mu \mathrm{m}\left({ }^{51} \mathrm{Cr}\right.$ tagged)

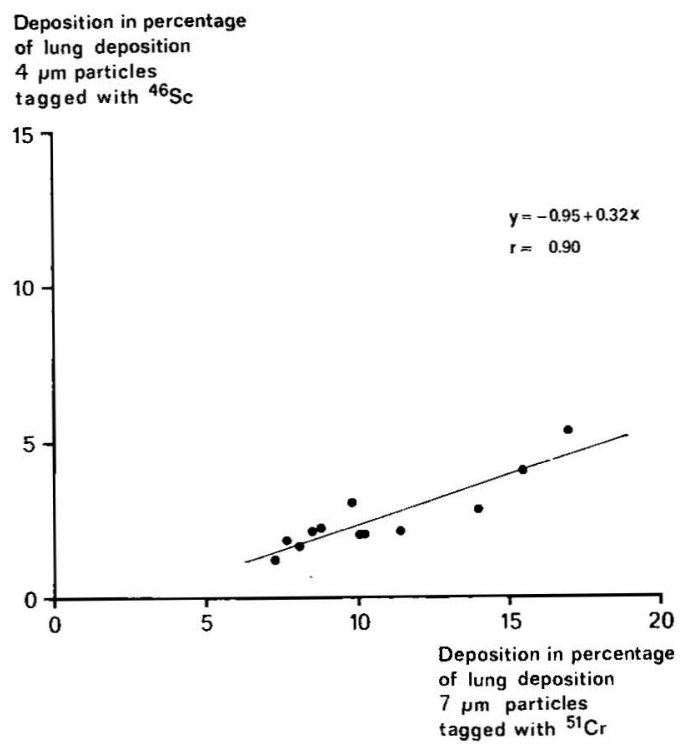

Fig. 1. Tracheobronchial deposition as the percentage of lung deposition in 12 rabbits exposed to a mixture of $7 \mu \mathrm{m}\left({ }^{51} \mathrm{Cr}\right.$ tagged) and $4 \mu \mathrm{m}$ $\left({ }^{46} \mathrm{Sc}\right.$ tagged) polystyrene aerosols. polystyrene particles via the oral tube averaged $27 \%$ with a standard deviation of $12 \%$. Breathing frequency varied among the rabbits (11-48 inhalations/ min). The average tracheobronchial deposition of $7 \mu \mathrm{m}\left({ }^{51} \mathrm{Cr}\right.$ tagged) polystyrene particles in 12 rabbits exposed via a tracheal tuibe had been $10.7 \%$ with a standard deviation of $3.2 \%$. The average tracheobronchial deposition in rabbits exposed via an oral tube was thus nearly three times higher than that in rabbits exposed via a tracheal tube. The difference is significant $(\mathrm{p}<0.05)$.

\section{Deposition after exposure to an anticholinergic drug}

In the 13 rabbits exposed intravenously to the anticholinergic compound atropin and in the 13 rabbits treated with saline the tracheobronchial deposition of $6 \mu \mathrm{m}$ teflon particles was, on the average, $25 \%$ in both groups with no significant difference in the standard deviation ( $8 \%$ and $9 \%$, respectively).

The anticholinergic effect of atropin was controlled in three rabbits by the measurement of any increase in airway resistance (24) when the rabbits were exposed intravenously to carbachol $(50 \mu \mathrm{g})$ after receiving the atropin injection. No increase was found.

\section{Bronchial diameter and deposition}

The tracheobronchial deposition of $7 \mu \mathrm{m}$ $\left({ }^{51} \mathrm{Cr}\right.$ tagged) polystyrene particles in 14 rabbits was studied in relation to the inner bronchial diameter.

The deposition in all bronchial sections from the right lower lobe was significantly negatively correlated $(r=-0.62)$ with the average diameter of the bronchial sections from the right lower lobe (fig. 2). The deposition per square millimeter was also significantly negatively correlated $(\mathrm{r}=$ -0.71 ) to the average inner diameter. The significant negative correlation between diameter and deposition couples a smaller bronchial diameter with a greater deposition of particles. 


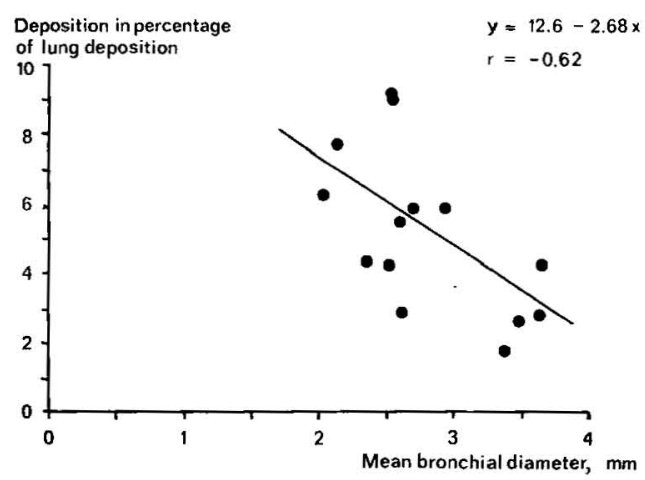

Fig. 2. Deposition of $7 \mu \mathrm{m}\left({ }^{51} \mathrm{Cr}\right.$ tagged) polystyrene particles in relation to the mean diameter of the main bronchus with its extension from the right lower lobe in 14 rabbits. Deposition is given as the percentage of lung deposition. The mean diameter of the lobe bronchus with its extension is given in millimeters.

\section{DISCUSSION}

The method used to determine tracheobronchial deposition is based on the measurement of deposition in terms of the particle content in those parts of the tracheobronchial tree that are possible to dissect free. Altogether this procedure accounts for only $10 \%$ of the total surface area of the tracheobronchial tree (exclusive of respiratory bronchioles), according to measurements by Kliment (8). The fraction of 4-7 $\mu \mathrm{m}$ particles deposited in the free dissected part of the tracheobronchial tree is one-tenth to one-fifth of the fraction cleared during the first phase of lung clearance (during the first one or few days) after inhalation in rabbits (7).

The method of studying deposition by free dissection can be used only on experimental animals. It is thus of interest to know whether the deposition patterns obtained in rabbits are comparable with those in humans. Smaller animals have a greater lung deposition for particles $>1$ $\mu \mathrm{m}$, and this phenomenon is attributed by Palm et al. (13) to a larger tracheobronchial deposition. On the other hand theoretical studies (8) indicate a similarity in lung deposition between man and rabbit. That regional deposition varies largely according to particle size is in agreement with theoretical calculations $(8,9)$ and an earlier experiment (23) on rabbits, in which the bronchial deposition of $7 \mu \mathrm{m}$ particles was greater than that of $2 \mu \mathrm{m}$ particles.

The biological factor causing interindividual differences in deposition influenced the deposition of 4 and $7 \mu \mathrm{m}$ particles in the same direction and in proportion to each other. Such a conclusion verifies the human studies made by Lippmann et al. (11). They found that the variation of the tracheobronchial deposition according to particle size (in the size range 2-12.5 $\mu \mathrm{m}$ ) was characteristic for a certain individual, while the differences in deposition between individuals were considerable.

Perhaps the difference in deposition with exposure techniques is attributable to the fact that a constriction in the airways, such as the vocal cords, produces a higher deposition just distal to the constriction (15). Respiratory differences between the two exposure techniques might also be important to the average difference in deposition.

Treatment with atropin $(0.5 \mathrm{mg} / \mathrm{kg}) \mathrm{did}$ not change the tracheobronchial deposition of inhaled $6 \mu \mathrm{m}$ teflon particle aerosols in rabbits. Atropin prevents nervously mediated bronchoconstriction and abolishes the resting tone of the airways (25). This result implies that physiological contractions in control animals, as well as possible aerosol-induced contractions, are of minor importance to the explanation of interindividual differences in deposition.

The significant negative correlation between diameter and deposition implies that differences in deposition among individuals in earlier studies $(20,21,22)$ depended at least to some extent on differences in bronchial diameters.

In conclusion, the results show that the tested ways of varying the particle size and exposure technique affect the tracheobronchial deposition to about the same extent $(300 \%)$ as the individual variation caused by the biological factor. Moreover, such anatomical factors as bronchial diameter seem to be more likely candidates for the biological factor than such physiological factors as bronchoconstriction. 


\section{REFERENCES}

1. BEECKMANS, J. M. The deposition of aerosols in the respiratory tract: 1. Mathematical analysis and comparison with experimental data. Can. j. physiol. pharmacol. 43 (1965) 157-172.

2. CAMNER, P. The production and use of test aerosols for studies of human tracheobronchial clearance. Environ. physiol. 1 (1971) $137-154$.

3. CAMNER, P., PHILIPSON, K. and LINNMAN, L. A simple method for nuclidic tagging of monodisperse fluorocarbon resin particles. Int. j. appl. radiat. isot. 22 (1971) $731-734$.

4. DALHAMN, T. Mucous flow and ciliary activity in the trachea of healthy rats and rats exposed to respiratory irritant gases. Acta physiol. scand. 36 (1956): suppl. 123, $161 \mathrm{p}$.

5. FINDEISEN, W. Über das Absetzen kleiner, in der Luft suspendierter Teilchen in der menschlichen Lunge bei der Atmung. Pflügers arch. 236 (1935) 367-379.

6. HATCH, T. F. and GROSS, P. Pulmonary deposition and retention of inhaled aerosols. Academic Press, New York, N.Y. 1964. $192 \mathrm{p}$.

7. HOLMA, B. Lung clearance of mono- and di-disperse aerosols determined by profile scanning and whole-body counting: A study on normal and $\mathrm{SO}_{2}$ exposed rabbits. Acta med. scand. (1967): suppl. 473, 102 p.

8. KLIMENT, V. Similarity and dimensional analysis, evaluation of aerosol deposition in the lungs of laboratory animals and man. Folia morphol. (Praha) 21 (1973) 5964.

9. LANDAHL, H. D. On the removal of airborne droplets by the human respiratory tract: 1. The lung. Bull. math. biophys. 12 (1950) $43-56$.

10. LIPPMANN, M. and ALBERT, R. E. The effect of the particle size on the regional deposition of inhaled aerosols in the human respiratory tract. Am. ind. hyg. assoc. j. 30 (1969) $257-275$.

11. LIPPMANN, M., ALBERT, R. E. and PETERSON, H. T., JR. The regional deposition of inhaled aerosols in man. In: W. H. WALTON (ed.), Inhaled particles III. Unwin Brothers Ltd., Old Woking, Surrey 1971, pp. $105-120$.
12. MERCER, T. The deposition model of the Task Group on Lung Dynamics: A comparison with recent experimental data. Health phys. 29 (1975) 673-680.

13. PALM, P. E., MC NERNEY, J. IM. and HATCH, T. Respiratory dust retention in small animals. Arch. ind. health 13 (1956) $355-365$.

14. PHILIPSON, $K$. On the production of monodisperse particles with a spinning disc. Aerosol sci. 4 (1973) 51-57.

15. PROETZ, A. W. Air currents in the upper respiratory tract and their clinical importance. Ann. otol. rhinol. laryngol. 60 (1951) $439-467$.

16. STUART, B. O. Deposition of inhaled aerosols. Arch. intern. med. 131 (1973) 6073.

17. SUDLOW, M. F., OLSON, D. E. and SCHROTER, R. C. Fluid mechanics of bronchial air-flow. In: W. H. WALTON (ed.), Inhaled particles III. Unwin Brothers Ltd., Old Woking, Surrey 1971, pp. 19-29.

18. TASK GROUP ON LUNG DYNAMICS. Deposition and retention models for internal dosimetry of the human respiratory tract. Health phys. 12 (1966) 173-207.

19. TASK GROUP ON METAL ACCUMULATION. Accumulation of toxic metals with special reference to their absorption, excretion and biological half-times. Environ. physiol. biochem. 3 (1973) 65-107.

20. TOMENIUS, L. A method for determining the retention of inhaled particles in a bronchus. Environ. physiol. biochem. 3 (1973) 1-12.

21. TOMENIUS, L. A study on the role of deposition for tracheobronchial clearance. Environ. physiol. biochem. 3 (1973) 111116.

22. TOMENIUS, L. A study on tracheobronchial deposition and 2-hour retention in rabbits. Environ. physiol. biochem. 5 (1975) $1-7$.

23. TOMENIUS, L. Deposition of 2 and $7 \mu \mathrm{m}$ particles in the rabbit lung. Am. rev. respir. dis. 115 (1977) $29-32$.

24. TOMENIUS, L., STRANDBERG, $K$. and CAMNER, $P$. The influence of a carbachol aerosol on the tracheobronchial deposition of $99 \mathrm{~m}$ Tc tagged particles. Environ. physiol. biochem. 5 (1975) 78-83.

25. WIDDICOMBE, J. G. Regulation of tracheobronchial smooth muscle. Physiol. rev. 43 (1963) $1-37$. 